\title{
Evaluación y perspectivas de la introducción del cine digital desde el punto de vista del exhibidor
}

Marta Batlle Beltrán, Manuel Mateo Doll

https://doi.org/10.37610/dyo.v0i71.581
Recibido: 20 de Marzo de 2020

Aceptado: 30 de Abril de 2020

\section{Resumen}

El negocio cinematográfico se ha visto inmerso en el desarrollo tecnológico y las innovaciones de los últimos años, básicamente la introducción de la tecnología digital, aunque también la globalización o la televisión de pago. Todo ello ha comportado efectos como reducir el ciclo de vida del producto película en la sala de cine o los costes al implantar outsorcing en la producción. Este trabajo analiza el nuevo modelo de negocio cinematográfico según el exhibidor. Las conclusiones se derivan de la valoración de algunos exhibidores cinematográficos de España analizando decisiones como la renovación de proyectores en este cambio de gestión.

\section{Palabras clave}

Cine, distribución, tecnología digital, espectadores, VPF.

\section{Introducción sobre el negocio cinematográfico}

El cine, al igual que cualquier otro tipo de negocio, además de las consideraciones de índole cultural y social, existe para obtener beneficios. Si se asimila a las etapas del producto película que se hace llegar a los clientes, Dadek (1962) describe las bases sobre las que se asienta la industria cinematográfica: producción, distribución y exhibición. Son tres procesos totalmente integrados que funcionan como un engranaje; si aumenta la demanda (exhibición), aumenta la producción y consecuentemente la distribución:

- la producción, que engloba la investigación, el desarrollo y la fabricación;

- la distribución consiste en la venta al por mayor del producto final (la película);

- y la exhibición consiste en la venta al por menor del producto final (la película).

\section{Marta Batlle Beltrán *}

marta.batlle@upc.edu

ORCID ID: 0000-0002-2088-5841

\section{Manuel Mateo Doll ** manel.mateo@upc.edu ORCID ID: 0000-0002-3975-9116}

* Departamento de Tecnología de la Arquitectura / EPSEB. Universitat Politècnica de Catalunya. Av. Doctor Marañón, 44-50, 08028 Barcelona, España.

** Departamento de Organización de Empresas / IOC / ET SEIB. Universitat Politècnica de Catalunya. Av. Diagonal $647,7^{\circ}, 08028$ Barcelona, España
Cuevas (1999) considera la película como un producto sui generis, un producto que no se parece a ningún otro. Aunque la política comercial de ventas sea similar a otros productos, es un producto de fabricación artístico-industrial. En la misma línea, Ferran (2007) considera que el producto audiovisual es único, un producto que difícilmente admite la investigación y el desarrollo de otro tipo de productos; la producción audiovisual es arte con la pretensión de llegar al gran público, es arte para masas. La industria cinematográfica es un negocio complicado de analizar, ya que puede conducir a grandes beneficios o inversamente, a grandes pérdidas.

Analizando cada una de estas bases sobre las que se asienta el negocio cinematográfico

- el negocio de la producción obtiene los beneficios mediante la elaboración de películas;

- el negocio de la distribución obtiene los beneficios resultantes del diferencial de comprar los derechos al productor y cederlos al exhibidor $\mathrm{y}$,

- por último, el negocio de la exhibición obtiene los beneficios resultantes entre los ingresos en taquilla, deduciendo los gastos de explotación, y otros ingresos no relacionados con las películas (venta de palomitas o refrescos, entre otros).

El negocio cinematográfico fue creado como un oligopolio, las llamadas majors, y en esa forma se ha mantenido a lo largo de las décadas (Gomery, 1986; Robins, 1993; Augros, 2000; Segovia, 2004). Una major es una compañía cinematográfica que se dedica tanto a la producción, distribución y exhibición de películas. Son seis (The Walt Disney Company. Warner Bros Entertainment, News Corporation, Viacom, 
Sony Corp., NBC-Universal y Time Warner) que conjuntamente dominan más del $80 \%$ de la recaudación mundial. Gomery (1998) y Wasko (1994) coinciden en afirmar que las dimensiones de estos conglomerados podrían atribuirse al aprovechamiento de las sinergias en la confluencia entre los diferentes segmentos de los medios de comunicación y entretenimiento. La industria cinematográfica obtiene sus beneficios mediante la distribución de sus contenidos en cines, DVD, pay per view (PPV), cable y televisión entre otras. Las posibilidades que ofrecen las nuevas tecnologías tampoco han escapado a la atención de estos gigantes para monopolizar el mercado mundial (Segovia, 2004). Otros cambios relevantes (Scott, 2004) son la intensificación de la descentralización geográfica de las actividades para el rodaje de películas (lejos del núcleo complejo de Hollywood), la proliferación de nuevos mercados basado en el envasado y reenvasado de la propiedad intelectual de los derechos de

Figura 1 Ejemplo de los tipos de concentración para productos diferentes en la industria cinematográfica Fuente: Elaboración propia..

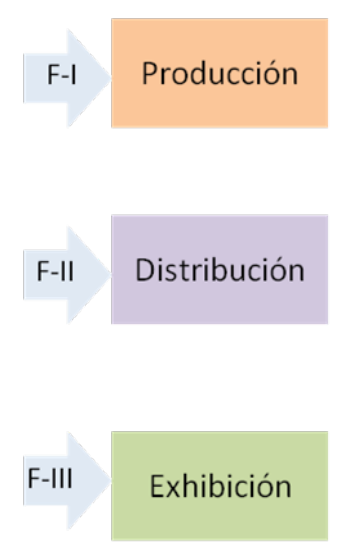

No es tarea fácil la localización de cifras de estos conglomerados mediáticos. Por esta razón algunos investigadores que estudian esta industria obtienen los datos mediante prensa especializada (Variety, 2020; Box Office 2020; The Hollywood Reporter, 2020; Screen International, 2020). En este trabajo se han utilizado estas mismas fuentes. Otros datos provienen de anuarios y publicaciones corporativas, entre otros. En principio son publicaciones fiables con la información muy actualizada. Un caso especial es la Motion Picture Association of America (MPAA, 2020). Esta asociación se gestiona como un cártel exclusivo de los intereses de las majors donde se aporta información valiosa.

La estructura del artículo es la siguiente. En la sección 2, se presentan los fundamentos de la industria cinematográfica, en base a los tres procesos descritos, así como las relaciones comerciales entre distribuidor y exhibidor, y en la sección 3 se describe la película como producto de la industria cinematográfica y su incidencia en las diferentes ventanas de explotación. En la sección 4 se analiza el modelo estratégico propiedad y la fusión de las majors en grandes conglomerados de medios de comunicación. Este tipo de empresas que fabrican el mismo producto van ocupando espacios mayores en el mercado a costa de que otras desaparezcan, proceso denominado concentración. Calvet et al. (1997) consideran la concentración como la variable más importante de las que definen la estructura de un mercado, dado que clasifica los mercados en monopolio, oligopolio y competencia perfecta. Dichos autores diferencian tres tipos de concentración: horizontal, vertical y conglomerados.

En la Figura 1 se muestra un ejemplo de los dos tipos de concentración aplicados a la industria cinematográfica: la vertical en el caso del cine supone que una major produce, distribuye y tiene uno o varios canales de exhibición; la horizontal en el caso del cine distribuye el producto mediante diferentes ventanas de exhibición.

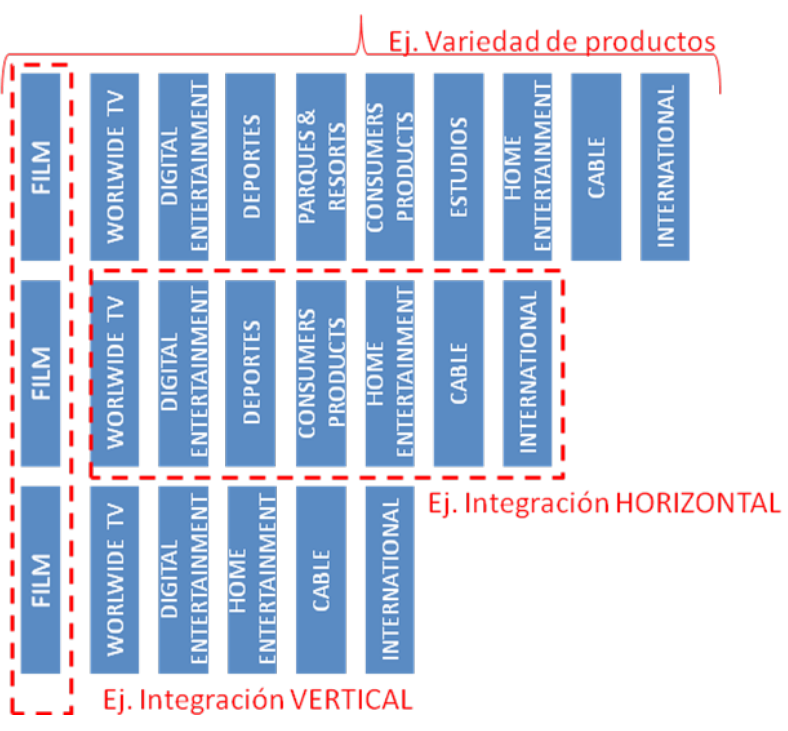

del negocio cinematográfico completado en la sección 5 con una valoración de lo que ha significado implementar la tecnología digital en las salas de cine. En la sección 6 se muestra el trabajo de campo realizado con una encuesta a los exhibidores de salas de cine sobre la digitalización y sus consecuencias futuras. Finalmente, en la sección 7 se exponen las conclusiones.

\section{Procesos y agentes de la industria cinematográfica}

\subsection{El proceso de producción}

La actividad industrial de producción se basa en diseñar, financiar y realizar materialmente las películas, incluyendo la organización de todas las fases hasta la obtención del negativo. A partir de esta matriz, los laboratorios realizan las copias en el soporte establecido, denominadas copias de explotación. Dichas copias pueden estrenarse en diferentes ventanas, tema que se abordará en este artículo. 
Desde el punto de vista macroeconómico, Ferran (2007) destaca como factores más relevantes que afectan a la industria de la producción audiovisual: los ciclos económicos, las variaciones del tipo de cambio entre divisas en el mercado monetario, la implicación de las administraciones y los cambios de los tipos de interés. Desde el punto de vista microeconómico, sin embargo, destaca como factores más relevantes: la evolución de las nuevas tecnologías que facilitan el proceso de producción y las barreras de entrada para estar al nivel de las grandes empresas. Cuevas (1999) afirma que "la producción cinematográfica está gobernada mundialmente por empresas especializadas en esta actividad, asociadas, o no, a otras, a su vez especializadas en el comercio internacional de audiovisuales". Las dimensiones, tamaños y organizaciones son muy diversas de uno a otro país. De las grandes compañías norteamericanas o japonesas a las empresas europeas, mayoritariamente de carácter artesanal, hay un abismo. La producción de una película no es comparable con ninguna otra actividad económica general (Cuevas, 1999). Es decir, tiene un gran riesgo, sin que ello conlleve que, en conjunto, no pueda ser rentable.

\subsection{El proceso de distribución}

En 1916, las películas tenían que encontrar sala de exhibición y Adolph Zukor implantó dos fórmulas ampliamente conocidas en el sector:

- Con la contratación "por lotes", el exhibidor tenía que llevarse junto con la película importante otras de menos entidad.

- Con la contratación "a ciegas", el exhibidor contrataba toda la producción anual de un estudio, sin saber qué películas se realizarían.

Esta fórmula estuvo vigente hasta que se aplicó la Ley Anti-trust (Sherman, 1980) lo que supuso para las productoras cinematográficas que se desvincularan de los otros dos sectores. La distribución cinematográfica empezó a moverse a partir de los años 50, fundamentalmente presionada por el control que ejercían las multinacionales desde los grandes estudios. Los distribuidores independientes pretendían conseguir rellenar los huecos en las salas, con películas impulsadas por productores independientes. Este fue el inicio y la consolidación del negocio cinematográfico en el resto del mundo. Las grandes distribuidoras han participado en algún tipo de colusión para limitar los pagos a los exhibidores (Moul, 2008).

El distribuidor es el vínculo más poderoso en la cadena de valor del producto y puede estar directamente relacionado o no con la producción o ser totalmente independiente. Augros (2000) incluye dentro del negocio de la distribución: los contratos con las salas de exhibición, presentar las películas a los exhibidores, determinar las re- muneraciones, las fechas de estreno, estipular las condiciones de proyección, determinar los precios de las entradas, establecer el calendario de duración de exhibición de la película en cartelera, organizar geográficamente la comercialización, determinar el número de copias, la publicidad, campañas de merchandising / licensing, envío y control de copias a salas, control de la recaudación y la calificación para los premios. La distribuidora debe valorar los contenidos de la producción para su comercialización considerando la temática, el tratamiento y la duración. También es importante considerar para comercializar territorios, idiomas, canales y ventanas e imprescindible disponer del material: fotos, dosier de prensa, sinopsis, material promocional, calidad, derechos, audios separados, guion definitivo, entre otros.

La distribuidora se lleva el mayor porcentaje de los ingresos brutos en las primeras semanas del pase de las películas y menos en las semanas siguientes, lo que es una forma de compensar sus esfuerzos de marketing. El porcentaje de taquilla que se paga a los distribuidores varía entre territorios. La participación del exhibidor en los EE.UU. oscila entre un $45 \%$ a $55 \%$ y en el resto del mundo, entre el $55 \%$ y el $65 \%$. El balance remitido del exhibidor al distribuidor se denomina Net Theatrical Rentals. En casi todos los países, las empresas de distribución tienen la posibilidad de distribuir la producción nacional conjuntamente con la de películas extranjeras. Linares (2008) diferencia en dos grandes grupos a las distribuidoras que participan en el mercado europeo: las majors que pueden tener sus filiales en cada territorio nacional o las joint-ventures entre filiales y grupos nacionales. Las empresas pueden estar integradas verticalmente hacia la producción cinematográfica a parte de la distribución o bien hacia la producción y exhibición cinematográfica. También pueden ser empresas que participan en los tres sectores (producción, distribución y exhibición), otras insertadas dentro de los grandes grupos mediáticos o distribuidoras independientes (centrando su actividad únicamente en la distribución cinematográfica)

\subsection{El proceso de exhibición}

El proceso de exhibición, último eslabón, tiene lugar cuando se da a conocer al público la película producida. La exhibición en salas de cine suele ser la primera ventana de explotación tradicionalmente. Autores como Wiese (1989) y Augros (2000) sitúan este proceso de exhibición en diferentes ventanas. En este proceso la empresa exhibidora se encarga de explotar el local donde se exhiben las películas y realiza el contrato con la distribuidora, que vincula la película con su pase en pantalla. A pesar de que esta industria se ha visto afectada por cambios en todos sus procesos, sin lugar a dudas las salas de cine son las más afectadas por los avances tecnológicos, tal y como se tratará en este artículo. 


\subsection{Relaciones comerciales entre el distribuidor y el exhibidor}

El distribuidor se lleva una parte del dinero que se recauda en el cine. La política de marketing de las distribuidoras es estrenar las películas de forma simultánea en un gran número de pantallas para generar un consumo rápido, partiendo de grandes campañas publicitarias. La mayor parte de la recaudación se concentra en las primeras semanas de exhibición. El sistema de facturación más extendido es el Film Rental, cobrar por parte del distribuidor un porcentaje sobre la facturación del exhibidor. Suele ser más favorable para el distribuidor que para el exhibidor. El distribuidor es quien decide el porcentaje, y pretende facturar el máximo con independencia del resultado que se obtenga en la taquilla. Las negociaciones son diferentes según sean con exhibidores independientes o grandes circuitos de exhibición (que disponen de muchas salas), que tienen una posición más ventajosa para negociar con la distribuidora.

El Film Rental es diferente en cada país, ya que dependerá entre otros factores del porcentaje de derechos de autor. La permanencia de la película en cartelera dependerá del éxito comercial. Si no funciona, se reemplaza por otra que tenga mayor expectativa comercial, siempre cumpliendo el mínimo exigido por contrato. El posicionamiento de la película en la sala de cine lo realiza el distribuidor y negocia las condiciones de alquiler de la película. El distribuidor busca salas donde pueda exhibir sus películas, aunque también puede ocurrir que el exhibidor tenga mucho interés en exhibir un título determinado. Las películas cada vez permanecen menos tiempo en cartelera y los exhibidores pueden realizar pocas prórrogas de los contratos, salvo que tengan múltiplex (multisalas). Además, los exhibidores han tenido que ir renovando los equipos de proyección para poder adaptarse a los nuevos formatos de la distribución, tema que se abordará más adelante. Esto les ha conllevado grandes inversiones económicas.

\section{La película como producto de la industria cinematográfica}

Los estudios de Hollywood han tratado de perfeccionar su modelo de negocio. Y lo han conseguido aumentando enormemente el coste de producir y promocionar las películas. Por ejemplo, la película Jurassic World ganó un total de 1.670 millones de dólares en todo el mundo, partiendo de un coste de 150 millones de dólares. Las actividades en este tipo de industria artístico-industrial se materializan mediante la cadena de valor del producto de fabricación en este caso artístico-industrial (Figura 2).

Las películas tienen otras muchas posibilidades de comercialización. El sistema de ventanas de distribución se implementó en los años 80 del siglo XX como fórmula para que una misma película no compitiera contra ella misma en diferentes canales, con el objetivo de maximizar los beneficios que una misma película podía conseguir primero en las salas de cine, segundo en DVD (entonces, en vídeo) y, finalmente, en alquiler y televisión. El ciclo de distribución de una película cuenta con unos plazos de exclusividad entre las diferentes ventanas que cada vez se acortan más. El rendimiento del producto continúa con la venta y alquiler de películas en otros formatos. El volumen de ingresos que generan acaparan el interés de las compañías del sector dado que se estima que en los cines se aproxima sólo al 20\% del total. 
Figura 2 Cadena de valor del producto artístico-industrial película

Fuente: Elaboración propia.

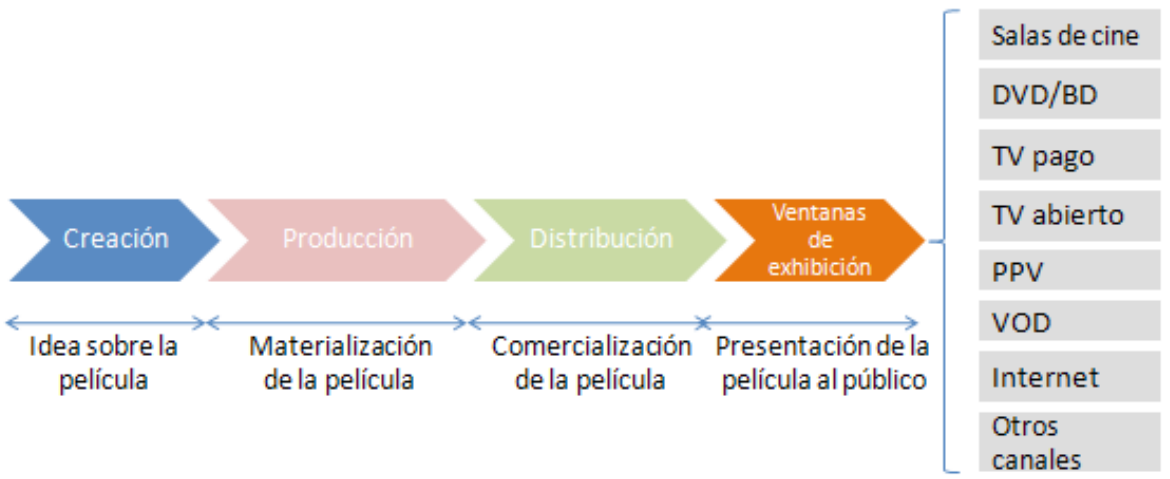

El mercado de la distribución se divide en doméstico, cuando el lanzamiento de la película se realiza en Estados Unidos y Canadá, e internacional, para el resto del mundo. Se describen a continuación las diferentes ventanas de explotación que la industria ha creado para maximizar los ingresos en cada etapa de la cadena de valor:

- (V1) Theatrical: relacionado con el estreno en el cine (es decir, en las salas de cine).

- (V2) Entretenimiento en el hogar (Home Video o Home Ent): el lanzamiento de la película se realiza en DVD, Blu-Ray y en servicios de transmisión en línea.

- $\quad$ (V3) TV de pago: canales de televisión por suscripción. En el Reino Unido, esto incluye Sky Cinema y en las redes de cable de EE. UU sería HBO.

- (V4) TV en abierto: normalmente es de servicio público y/o con publicidad.

- (V5) Video on Demand (VOD): servicios de transmisión en línea (como iTunes, Netflix y Amazon Prime).

- $\quad$ (V6) Pay Per View (PPV): donde el espectador paga por ver una transmisión cifrada y programada de la película.
Con la intención de reducir los gastos y aprovechar los esfuerzos de promoción en todas las ventanas descritas anteriormente, los plazos entre el estreno en cine y su lanzamiento en DVD/BD y otras ventanas tienden a reducirse cada vez más. Los plazos de exhibición después de la primera ventana (salas) han pasado de los 6 meses, que era habitual, a los 3 meses. Incluso algunas películas se lanzan en DVD/BD al cabo de un mes de su estreno en cines, si la película no tiene buena aceptación en el cine. Transcurrido un plazo, se distribuye a las televisiones de pago y finalmente a las televisiones en abierto (Figura 3). Las circunstancias actuales han forzado a que se inviertan las prioridades de explotación de algunas ventanas. El cambio del modelo tradicional de negocio es evidente y las distribuidoras plantearán sus estrategias comerciales a fin de buscar la ventana de explotación más lucrativa para sus intereses. Fernández et al. (2009) destacan en su trabajo de investigación que la televisión y el vídeo no son sustitutos ni bienes complementarios en el caso de los amantes del cine. En la Figura 3 se muestra gráficamente las ventanas de exhibición en la parte superior y en la parte inferior los meses de duración en las diferentes ventanas de exhibición por países (filas) basado en un trabajo de investigación (Batlle, 2014), que servirán de referencia para comparar los datos con la situación actual. 
Figura 3 Comparativa por países sobre los meses de duración en las ventanas de exhibición después del pase en cine (2014). * DTO Transferencia de datos objeto

Fuente: Screen Digest/Elaboración propia

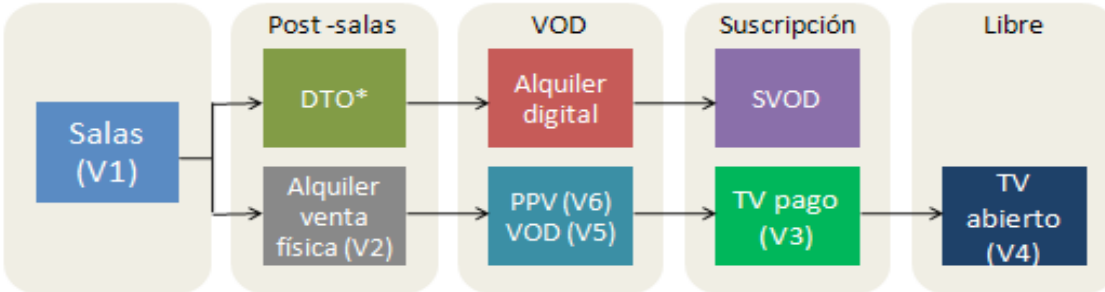

\begin{tabular}{lcccc}
\hline Alemania & $3-4$ & $9-12 / 6-9$ & 18 & 30 \\
\hline España & $3-4$ & $12 / 12-14$ & $14-16 / 12-14$ & 24 \\
\hline Estados Unidos & 3 & $4-8$ & $9-12 / 12$ & $27-30$ \\
\hline Francia & $3-4$ & $9-7,5$ & 12 & $27-30$ \\
\hline Italia & $3-4$ & 6,5 & 12 & 24 \\
\hline Reino Unido & $3-4$ & $8 / 6-9$ & 12 & $24-27$ \\
\hline
\end{tabular}

En cuanto a la obtención de cifras de las otras ventanas diferentes de las salas es un dato bastante complicado porque a diferencia de las salas, es más amplio, diverso y mantiene los números privados. Sólo se han conseguido datos de Gran Bretaña. Paradójicamente, la mayor fuente de ingresos proviene actualmente de la televisión. Mientras que en la década de los 90, los acuerdos televisivos también representaban la mayor fuente de ingresos, el auge del DVD significó su apogeo en 2004, cuando las ventas físicas y los alquileres en conjunto alcanzaron el $51 \%$ de los ingresos totales de películas. En los últimos años, el video físico ha caído y en 2016 representó el 15\% de los ingresos del cine del Reino Unido. Esto significa que los ingresos de las licencias de televisión han recuperado su primer lugar y ahora representan casi el $40 \%$ de los ingresos de películas.

El coste de lanzar una película es muy alto: impresiones digitales para enviar a los cines y una gran campaña de marketing para el lanzamiento. El VOD sigue evolucionando con una cierta importancia durante la última década. Este dominio se observa en el cambio de los patrones de lanzamiento de películas. Históricamente, la denominada tercera ventana destinada al entretenimiento en el hogar era un flujo crítico de ingresos para las películas. Actualmente, en algunos casos, se ha invertido la secuencia de lanzamiento en las ventanas. Las películas se transfieren de forma más rápida de las salas de cine a los hogares. En el año 2000, las películas de los estudios de Hollywood se lanzaron en video aproximadamente 171 días después de su estreno theatrical inicial (casi seis meses después). En 2017, este promedio fue de 105 días, lo que representa una disminución del 39\%.

Los exhibidores de cine no ven positivamente esta situación; es una amenaza para sus negocios el poder perder su ventana de exclusividad (primera ventana). La producción de Netflix está creciendo en gran escala y a gran velocidad. Los estudios de Hollywood tardaron en aprovechar el potencial de Video on Demand (VOD) y, en cierta forma, están pagando esa renuncia; les ha surgido una nueva competencia de los servicios de VOD de suscripción ya que pueden producir y distribuir sus propias producciones de gran presupuesto.
Como datos interesantes, cabe mencionar que en 2015 Netflix lanzó 8 largometrajes de producción propia y ya en 2016 fueron 28. Otro competidor en el mercado SVOD es Amazon Studios, una nueva fuerza en la producción artística que busca aumentar su participación en el mercado mediante la producción de películas originales y adquisiciones exclusivas. El enfoque de Amazon parece ser muy diferente al de Netflix, al estar más abiertos a suscribir acuerdos flexibles con los cineastas. Algunos proyectos respaldados por Amazon se han lanzado en los cines antes de aparecer en Amazon Prime, mientras que Netflix parece no estar dispuesto a permitir que las películas tengan una ventana theatrical.

\section{Modelo estratégico de la industria del cine}

El negocio cinematográfico se puede analizar siguiendo el modelo de competitividad creado por Porter (2009). Para conseguir estrategias que aprovechen las fuerzas competitivas (oportunidades) y se defiendan de las amenazas, las cinco fuerzas que definen la estrategia de las empresas son: poder de negociación del proveedor; poder de negociación del cliente; amenaza de nuevos competidores; amenaza de productos sustitutos y rivalidad entre los competidores.

Koontz et al (2012) afirman que la formulación de estrategias que sugiere Porter (2009) precisa de un análisis que muestre el atractivo que posee una industria. Si partimos sobre la base del análisis de la industria, se pueden adoptar estrategias genéricas que podrán adecuarse a diferentes tipos de organizaciones en su sentido más amplio; cabe destacar que cualquier empresa puede usar más de una estrategia. Daft (2011) destaca que para formular la estrategia, el modelo de Porter es eficaz fundamentalmente para determinar la posición de una empresa frente a los competidores. Asimismo, Hill y Jones (2009) consideran que el modelo de Porter contribuye a identificar las oportunidades y amenazas. Mediante las cinco fuerzas competitivas se analiza qué variables pueden influir en el negocio cinematográfico 
1. Poder negociador de los proveedores: Esta fuerza competitiva se basa en calcular la influencia que tienen sobre los cines las empresas que suministran las materias primas, en este caso las distribuidoras, y el resto de componentes necesarios para satisfacer la proyección de la película. Los proveedores, productoras-distribuidoras, pueden modificar el precio de los productos y la calidad de las películas. Dentro de los productos que ofrece el proveedor, el cine norteamericano supera al resto.

2. Poder negociador de los compradores: En este negocio los consumidores eligen entre las diferentes opciones y pagan por ver las películas. Los clientes ven de forma sustantiva como su poder se ve disminuido. Los precios actuales de las entradas a salas de cine son altos, por lo que no están al alcance de todos. Actualmente los cines tratan de acercarse al gran público con varias iniciativas: precio de entrada low cost, día del espectador y fiesta del cine entre otras. Otro tipo de público opta por el alquiler de películas mediante la descarga directa, gratuita e ilegal que ofrece Internet o bien en videoclubs. Debido a Internet, se podría afirmar que los consumidores de cine consiguen reducir la influencia de los proveedores sin igualarla.

3. Amenaza de nuevos competidores: En los últimos años las salas de cine han sufrido un descenso notable de público. Difícilmente un emprendedor apostaría por el sector, debido a las barreras de entrada, cuantiosas si se comparan con otros sectores de ocio (coste del local, equipamiento de proyección, sonido y butacas, entre otras). Los que triunfan son más bien cadenas o circuitos consolidados repartidos por todo el país, barrera para otros competidores.

4. Amenaza de productos sustitutos: Quizá es el problema más grave que ha tenido que afrontar el sector, fundamentalmente por la aparición de la piratería. Asimismo, los DVDs suponen un producto sustitutivo al cine, al igual que el streaming con las ofertas que ofrecen plataformas como Netflix, HBO, Filmin, Amazon y Disney entre otras. La televisión también se puede considerar un sustitutivo del cine.

5. Rivalidad entre los competidores: Las cadenas de exhibición compiten entre sí de diferentes formas: desde ofrecer la posibilidad de ver películas en 3D, sonido 3D (Dolby Atmos) o tecnología ScreenX hasta butacas Full Recliner o 4DX. Además, otros métodos de diferenciación podrían ser la tarjeta fidelidad, tarjetas bono, días especiales para pase de películas VO o días para reposición de películas.

\section{Tecnología digital en salas de cine}

\subsection{Definición y caracter sticas del cine digital}

Se denomina cine digital al que utiliza la tecnología digital para distribuir y proyectar imágenes en movimiento y su proceso industrial se incluye en cada uno de los tres pilares de la industria (producción, distribución y exhibición). Partiendo de la base de una imagen correctamente filmada y unas copias para reproducción técnicamente correctas, el cine digital tiene mucha más calidad que el cine analógico. Una sala de cine digital debe tener capacidad para ofrecer al público alta definición de imagen, audio y subtítulos. Ello obliga a los exhibidores a actualizarse continuamente siguiendo los últimos avances tecnológicos y a realizar las oportunas inversiones.

Esta tecnología ha revolucionado la industria del cine en todos sus aspectos. En el cine digital se graba una representación digital del brillo y el color en cada píxel de la imagen y se proyecta la película utilizando un proyector digital, mientras que en el cine analógico la imagen queda fijada por una emulsión química en el filme de celuloide y se proyecta mecánicamente. La película obtenida mediante tecnología digital se puede distribuir en diferentes formatos: disco óptico, disco duro o vía satélite. El proceso digital permite una reproducción perfecta de las imágenes al cabo de un millón de proyecciones.

Los proyectores láser se están abriendo camino en las salas de cine. Estos proyectores integran un sistema de luz láser modular con un cabezal proyector que permite a los cines proyectar imágenes de láser muy nítidas y deslumbrantes. Este sistema de iluminación tiene una durabilidad mayor, incluso hasta 10 veces superior. Otro avance tecnológico importante ha sido la aparición de las pantallas con tecnología LED (Samsung ha sido la empresa pionera), un diseño modular de muchos paneles con miles de píxeles. Con esta tecnología la sala no necesita proyector pero si necesita abastecerse de los recambios para poder sustituir los paneles, lo que encarece considerablemente el producto. Con el paso del tiempo para equipos digitales no se desgasta el material fotosensible, no hay cortes, ni rayaduras, ni polvo; otra cuestión es la obsolescencia del proyector digital, que tiene una vida útil más corta que el analógico (ver sección 6). Derivado de la proyección digital, ha surgido la necesidad de realizar un contrato de mantenimiento para los equipos digitales y sus consumibles 


\subsection{Repercusiones económicas en las dis- tribuidoras al pasar a tecnología digital}

Con el sistema digital se evitan los costes que supone la edición de copias para su comercialización. En opinión de Bustamante (2011), la digitalización de la producción y distribución permitirá en un futuro nuevas fórmulas comerciales de distribución. Con este sistema, la distribuidora mantiene en todo momento el control de la copia, porque todos los proyectores del mundo llevan un código, una especie de matrícula, que facilita su localización en todo momento. A título aproximado, la película de impresión puede costar unos 900€; suponiendo que se realizan 4.000 copias de una película de gran lanzamiento, esto supone un coste de 3,6 millones de euros.

Con el sistema digital, a parte del ahorro de costes, se presentan otros beneficios: respuesta más eficiente a la demanda, mejor calidad de imagen, mejor calidad de sonido, nuevas opciones en el estreno y nuevas oportunidades de negocio para los exhibidores. Algunos exhibidores estiman en un $30 \%$ los ingresos provenientes de los llamados contenidos alternativos, con beneficios que van directamente al exhibidor. No obstante, siguen obteniendo sus máximos beneficios con películas suministradas por los grandes estudios. Es un arma de doble filo, ya que con el proceso de digitalización, las majors y distribuidoras independientes también podrían reducir sus ingresos provenientes de las salas, debido a los contenidos alternativos. Como ejemplo, un concierto de música en directo puede resultar beneficioso para el exhibidor, pero puede interferir en los intereses de la distribuidora en lo que refiere a la programación.

\subsection{Exhibición cinematográfica con tecnología digital y modelo de financiación basado en VPF (Virtual Print Fee)}

En España casi el 100\% de las salas están digitalizadas. Inicialmente, este porcentaje dependía del plan de digitalización de las salas, según lo que decidían estas. Pero la situación actual es diferente. Las distribuidoras ya han dejado de suministrar copias analógicas, por lo que ahora las salas tienen que seguir las pautas de las distribuidoras. Muchos exhibidores independientes españoles (que se lo han podido permitir) se han visto obligados a digitalizar a marchas forzadas las salas para competir con los grandes circuitos, que digitalizaron todas sus salas a la vez. La etapa del cine digital está consolidada. Los exhibidores necesitan películas distribuidas en formato digital para exhibir en las salas digitales.

Para la digitalización de las salas, acondicionarlas con proyectores digitales de resolución $2 \mathrm{~K}$ y $4 \mathrm{~K}$, se necesita realizar una inversión considerable que a veces no es proporcional con los ingresos de taquilla, ya que se precisan los mismos equipos tanto si las salas son grandes $o$ pequeñas y los ingresos varían según esto. El elevado coste de los equipos ha dificulta o su implantación en salas más pequeñas. Muchos exhibidores eran muy reacios al cambio si no llegaban a un acuerdo compartido con las distribuidoras de películas. Las negociaciones llevaron a desarrollar una tasa de licencia de copia virtual o Virtual Print Fee (VPF), tasa que los distribuidores pagan para que se exhiba la película, permitiendo a los financieros o facilitadores obtener un retorno seguro de la inversión. Mediante esta fórmula de financiación los distribuidores no consideraron la posibilidad de cambiar las condiciones de alquiler de las películas, es decir, cambiar los porcentajes del Film Rental. Otra lectura sería que la VPF actúa como un mecanismo de financiación para la primera compra de equipos de cine digital en sustitución de los proyectores analógicos. Otros piensan que es una fórmula para la redistribución de los ahorros al distribuir copias digitales en lugar de impresiones de la película. Agentes del sector lo consideran un mecanismo eficaz, pero no perfecto (ver sección 6). El exhibidor podía comprar un proyector analógico por menos de $50.000 €$, con una vida media de 30-40 años; ahora con el sistema digital tiene mayor riesgo, por el posible fallo de los componentes y la obsolescencia tecnológica. La experiencia de otros sistemas parecidos demuestra un promedio de vida entre 5 y 10 años.

Este modelo presenta contradicciones desde su concepción, los cines más comerciales son los más beneficiados, mientras que los cines más pequeños obtienen menos prestaciones. $\mathrm{Su}$ aportación se puede considerar como una subvención para digitalizar los equipos de proyección (Figura 4). Esta aportación fue efectiva hasta el 31 de diciembre de 2013 para salas existentes y está previsto que en el año 2021 dejen de pagarse estas aportaciones para los equipos instalados desde el inicio de la VPF. En el caso de salas de nueva creación, el exhibidor ha tenido que autofinanciar el $100 \%$ de los equipos digitales. Así pues, las distribuidoras han financiado una parte de la instalación de los primeros equipos digitales, pero en cambio no se financia su renovación por obsolescencia. 
Figura 4 Esquema comparativo del coste de la copia analógica versus copia digital.

Fuente: Elaboración propia .

\section{Coste impresión (sistema analógico)}

Coste impresión

(sistema digital)

\section{Opinión de los exhibidores}

En el cuestionario realizado a algunos de los exhibidores de España, se han definido cuatro bloques: perfil del negocio del encuestado, ventanas alternativas al cine en la explotación (sección 3), implantación del sistema digital en las salas de cine (sección 5) y afectaciones económicas (sección 5). Para este trabajo, se han seleccionado las respuestas relativas a la digitalización de las salas de cine y sus consecuencias futuras. Las 17 respuestas de la muestra se pueden clasificar según perfil del exhibidor:

- $\quad$ el $47 \%$ son propietarios de hasta 19 salas,

- $\quad$ el $35 \%$ son propietarios de 20 a 99 salas,

- el $6 \%$ son propietarios de 100 a 200 salas,

- $\quad$ otro $6 \%$ son gerentes de 1 a 199 salas

- y el $6 \%$ restante son gerentes de más de 200 salas.
Además:

- En función del número de salas que explota cada uno: un $47 \%$ explota de 1 a 19 salas, un $6 \%$ de 20 a 39 salas, un $29 \%$ de 40 a 59 salas, un $6 \%$ de 60 a 79 salas, otro $6 \%$ de 80 a 99 salas y el $6 \%$ restante explota de 100 a 200 salas.

- $\quad$ El número de complejos que explota cada uno es un $53 \%$ de 0 a 4 complejos, un $41 \%$ de 5 a 9 complejos y el $6 \%$ restante, de 10 a 19 complejos.

- $\quad$ El $47 \%$ explotan salas a nivel local, el 29\% a nivel autonómico y el $24 \%$ a nivel nacional. Ninguno explota salas a nivel internacional.

Aunque sea bajo el número de respuestas obtenidas, el número de salas totales que gestionan es significativo y se considera suficiente para realizar una valoración más bien cualitativa.
Tabla 1 Ficha técnica de la investigación (cuestionario).

\begin{tabular}{cc}
\hline Universo & Exhibidores cinematográfico \\
\hline Ámbito & España \\
\hline Tamaño muestra & 17 cuestionarios \\
\hline Persona a quien se dirige la encuesta & Empresarios/gerentes \\
\hline & On line \\
\hline Realización &
\end{tabular}


Sobre las ventanas alternativas de explotación del cine (sección 3), considerando que el cine sólo supone un 20\% de ingresos y tiene un efecto escaparate, se preguntó si creían que en un futuro los cines deberían cobrar a las distribuidoras por exhibir las películas. Un 59\% de respuestas fueron afirmativas y el $41 \%$ restante, negativas. Además, un $95 \%$ considera muy alta la afectación de la piratería en la exhibición.

Sobre la tecnología digital en las salas de cine (sección 5), a la pregunta si el exhibidor cree que la calidad de imagen digital es superior a analógica, el $82 \%$ de las respuestas obtenidas afirma que siempre, el $12 \%$ que a veces y el restante $6 \%$ no contesta.
La respuesta sobre el coste medio anual de mantenimiento del equipo de proyección digital muestra resultados diversos (Figura 5):

- $\quad$ el 35\% opina que el coste es mayor de 3.000 euros;

- $\quad$ el $18 \%$ opina que el coste oscila entre 2.000 a 2.500 euros;

- $\quad$ el $12 \%$ opina que el coste es de 2.500 a 3.000 euros, otro $12 \%$ de 0 a 500 euros y otro $12 \%$ de 1.000 a 1.500 euros

- $\quad$ y un $6 \%$ opina que el coste varia de 500 a 1.000 euros.

Figura 5 Coste medio anual de mantenimiento de los equipos de proyección digital.

Fuente: Cuestionario elaborado en Google / Elaboración propia.

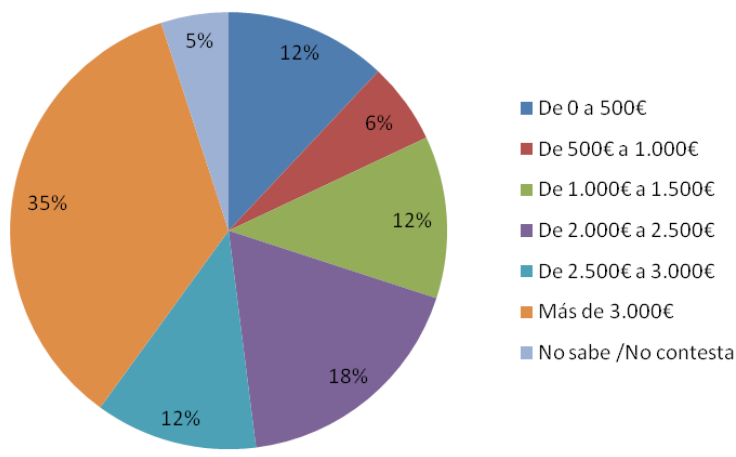

Al preguntar por el coste medio de un equipo de proyección digital (que incluye proyector, servidor y equipo de sonido, hay división de opiniones (Figura 6): el 42\% opina que el coste varía entre 40.000 y 60.000 euros, el $24 \%$ opina entre
60.000 y 80.000 euros, un $12 \%$ entre 80.000 y 100.000 euros, un $6 \%$ opina que hasta 20.000 euros, otro $6 \%$ de 20.000 a 40.000 euros y el último $6 \%$ de 100.000 a 150.000 euros.

Figura 6 Coste de un equipo de proyección digital.

Fuente: Cuestionario elaborado en Google / Elaboración propia.

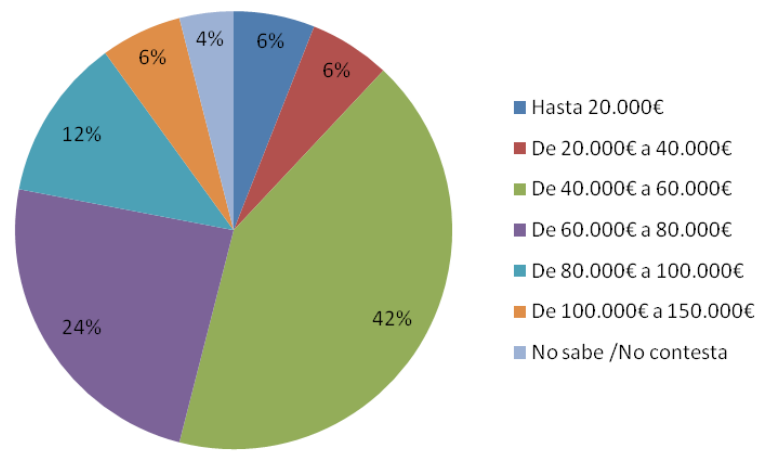

Referente a la durabilidad que considera el exhibidor que podrán tener los equipos digitales, el 12\% de respuestas considera una durabilidad de 0 a 5 años, el $76 \%$ de 5 a 10 años y el $6 \%$ de 10 a 15 años. El resto no lo sabe o no contesta. Algunos de los primeros proyectores instalados ya se han sustituido por falta de piezas de recambio lo que confirma la media del tiempo de vida citado anteriormente.
Preguntado el grado de satisfacción de la contribución VPF (apartado 5.3) que actualmente ceden las distribuidoras a los exhibidores, casi el 90\% manifiesta una satisfacción más bien baja en una escala de 1 a 7 (Figura 7). 
Figura 7 Grado de satisfacción de la contribución VPF del distribuidor al exhibidor.

Fuente: Cuestionario elaborado en Google / Elaboración propia.

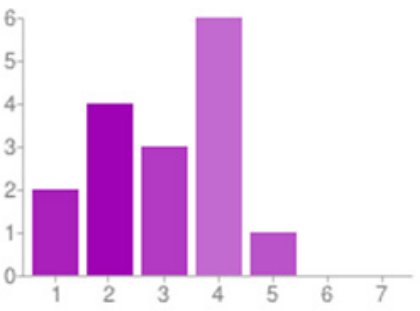

Muy bajo

Muy alto

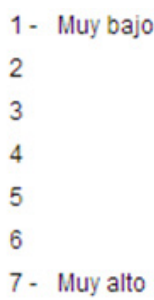

En cuanto a la repercusión de la obsolescencia de los proyectores digitales en las cuentas de explotación de sus negocios, tanto en la actualidad como en la próxima generación de equipos tras el fin de la VPF, en la mayoría de las respuestas se espera una repercusión alta, con un 53\% (Figura 8).
Figura 8 Repercusión de la obsolescencia de los proyectores digitales en las cuentas de explotación.

Fuente: Cuestionario elaborado en Google / Elaboración propia.

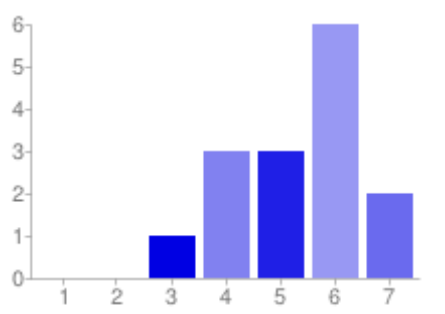

Muy baja
Muy alta

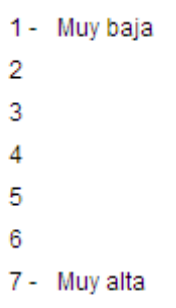

se benefician del ahorro que suponen las copias digitales. Con la digitalización de los equipos de proyección y su reducción de costes en copias, los exhibidores consideran que no ahorran nada. Dado que la tecnología avanza con celeridad, los exhibidores tendrán que crear un nuevo modelo de negocio para atraer a más espectadores: un modelo basado en que "el cine" impacte al espectador y añada realismo a la experiencia de ver una película. Ya existe alguna oferta en esta línea, con pantallas de gran formato, máxima definición en tecnología digital con $4 \mathrm{~K}$, salas con fenómeno multipantalla (ScreenX) que generan una sensación de inmersión de $270^{\circ}$ para que el espectador se sienta totalmente inmerso en la película, sonido Dolby ATMOS (primer sistema híbrido de sonido envolvente) o butacas con tecnología 4DX, entre otros. La llegada del streaming supone otro cambio importante en esta industria.

Con la finalida de facilitar su interpretación, se valoran las respuestas obtenidas de los exhibidores españoles en la tabla 2. La tabla muestra diferentes conceptos del negocio, la pregunta en cuestión formulada, la respuesta de los exhibidores y unas conclusiones sobre cada aspecto. 
Tabla 2 Conclusiones a partir del cuestionario de la investigación

\begin{tabular}{lcc}
\hline Concepto & Pregunta (P) & Conclusión \\
& Respuesta (R) & \\
\hline
\end{tabular}

La digitalización de salas en España (iniciada en 2007) se ha consolidado.
P. Durabilidad que podrán tener los equipos digitales.

R. E1 76\% considera que los equipos digitales pueden tenerla de 5 a 10 años
Según la opinión mayoritaria, la durabilidad de los equipos digitales es corta. Los exhibidores se tendrán que adaptar a los cambios. Las majors crean la necesidad de cambio, como oligopolio que forman; han consensuado los estándares tecnológicos y los han impuesto a los exhibidores, que no han podido negociar aspectos importantes como los costes operativos.
El exhibidor debe poder ofrecer contenidos alternativos proveídos por terceros en cualquier momento.
P. Conformidad con el pase de contenidos alternativos.

R. El 94\% está de acuerdo con el pase de contenidos alternativos.
Las imágenes en digital se pueden visualizar igual después de muchas proyecciones.
P. Calidad de imagen en cine digital es superior a la calidad de imagen en cine analógico.

R. El $76 \%$ afirma que es mayor la calidad del digital.
El aumento del pase de contenidos alternativos redundaría en un mayor negocio para el exhibidor. Con este nuevo escenario, las majors no tendrían la exclusiva ni el control de todos los contenidos. La sala sería un recinto donde se pueden pasar múltiples contenidos a un público que quiere salir de casa.

Opinión mayoritaria sobre que la calidad de la imagen del cine digital es superior a la del analógico. Las majors tienen poder suficiente para inducir a que las calidades de ambos tipos de imagen sean diferentes.

Se prevé una reducción del coste de los equipos digitales. El coste de los equipos de segunda generación bajará dos por proyector, servidor y equipo de sonido, que varía en función de su calidad.

P. Coste medio de un equipo de proyección digital.

R. Más de un $40 \%$ opinan que varía entre $40.000 €$ y $60.000 €$ y un $24 \%$, entre $60.000 €$ y $80.000 €$.

La VPF se creó como fórmula de financiación al no considerar las distribuidoras la posibilidad de cambiar las condiciones del Film Rental.

P. En caso que las majors no se hicieran cargo del coste completo de los equipos digitales en un futuro, cree que deberían bajar el porcentaje del Film Rental.

R. El 94\% lo cree.

Hasta ahora, la implantación del cine digital ha sido un mal negocio para el exhibidor, pero obedientemente lo ha cumplido porque no tenía otra opción. Ahora la VPF ya ha desaparecido.
La VPF sirvió para financiar los equipos digitales en la etapa de transición de cine analógico a digital.

P. Grado de satisfacción de la contribución VPF que actualmente ceden las distribuidoras.

R. El 90\% tiene una satisfacción baja.
Los exhibidores son conscientes de que no han hecho un buen negocio y lo asumen. El exhibidor que ha ido por libre no

El oligopolio de las majors decidirá y los exhibidores acatarán la decisión si quieren seguir accediendo al producto de estas (las películas). Se prevé que las majors, una vez más, ofrezcan casualmente una única opción. ha podido acceder a la VPF y ahora la VPF ya ha desaparecido.
Las distribuidoras financian parte y no la totalidad de la instalación de los primeros equipos digitales; incertidumbre sobre futuras renovaciones por obsolescencia.
P. La contribución de económica de las distribuidoras (para reponer equipos digitales actuales) debería seguir en el futuro.

R. El 94\% considera que sí. 
En trabajos futuros, se pretende continuar este estudio analizando las perspectivas de la evolución de la demanda incluyendo los nuevos competidores en la etapa de exhibición. Algunos de ellos, como las compañías telefónicas que para añadir valor ofrecen productos gratuitos o de pago a domicilio, podrán considerarse una opción híbrida entre las ventanas detalladas en la sección. En otra línea, se puede analizar la evolución de la compañía Netflix que realizan la doble actividad: son productores y exhibidores a la vez. Estas nuevas ofertas seguro que incidirán en las expectativas de los espectadores. Así, una vez analizada toda esta información, se podrían ofrecer una serie de recomendaciones a los exhibidores para garantizar el futuro de sus negocios.

\section{Bibliografía}

AUGROS, J. (2000). El dinero de Hollywood: Financiación, producción, distribución y nuevos mercados. Barcelona: Paidós Ibérica.

BATLLE, M. (2014). Análisis y perspectivas de la evolución del negocio cinematográfico desde la óptica de la distribución y exhibición. Tesis doctoral. UPC.

BUStAMANTE, E. (Ed.) (2011). Industrias creativas. Amenazas sobre la cultura digital. Barcelona: Gedisa.

CALVET, J.M.; LLINAS，X.; PUIGGERMANAL，R.; SOLE, F. (1997). Elements d'Economia Industrial. Barcelona: Institut Ciències de l'Educació de la Universitat Politècnica de Catalunya.

CUEVAS, A. (1999). Economía cinematográfica: la producción y el comercio de películas. Madrid: Cía. Audiovisual Imaginógrafo.

CHOUDHURY, S.; RAYMOND, K.; HIGGS, P. (2010). Ontology-Based Information Management: Exploiting User Perspective within the Motion Picture Industry. G. Chowdhury, C. Khoo, and J. Hunter (Eds.): ICADL 2010, LNCS 6102, pp. 254-255. Springer-Verlag Berlin Heidelberg.

COLLINS, A.; ZANOLA, R.; SCORCU, A.E. (2007) Distribution Conventionality in the Movie Sector: An Econometric Analysis of Cinema Supply. University of Portsmouth, University of Bologna and RCEA, University of Eastern Piedmont and RCEA.

COLLINS, A.; HAND, C.; RYDER, A. (2005). The lure of the multiplex? The interplay of time, distance, and cinema attendance, Environment and Planning. Pion Ltd, London, vol. 37(3), 483-501.

DADEK, W. (1962). Economía cinematográfica. Madrid: Rialp.
DAFT, R. L. (2011). Teoría y diseño organizacional $\left(10{ }^{\mathrm{a}}\right.$ ed.). México: Cengage.

DE VANY, A., WALLS, D. (1997). The market for Motion Pictures: rank, revenue and survival. Economic Inquiry. 783-797.

DELLAROCAS, C.; ZHANG, X.; AWAD, N. F. (2007). Exploring the value of on line product reviews in forecasting sales: The case of Motion Pictures. Journal on interactive marketing Vol 21, (4 ), 23-41.

DELRE, S. A.; WANDER, J.; BROEKHUIZE, T. L. (2008). The Effect Of Social Influence on Market Inequalities In The Motion Picture Industry. Advances in Complex Systems, 11, (2), 273-287.

DIAZ GANDASEGUI, V. (2011). Espectadores de 3D: ¿El futuro del cine?. ARBOR Ciencia, Pensamiento y Cultura, 187 (748), 429-438.

ELBERSE, A.; ELIASHBERG, J. (2003). Demand and Supply Dynamics for Sequentially Released Products in International Markets: The Case of Motion Pictures Marketing Science 22, (3), 329-354.

ELIASHBERG, J.; ELBERSE, A.; LEENDERS, M. (2006). The Motion Picture Industry: Critical Issues in Practice, Current Research \& New Research Directions. Marketing Science. 25, (6), 638-661.

EPStEIN EDWARD, J. (2007). The big Picture. The New Logic of Money and Power in Hollywood. Barcelona: Tusquets Editores.

FERNANDEZ-BLANCO, V., OREA, L. ; PRIETO-RODRIGUEZ, J. (2009). Analyzing consumers heterogeneity and self-reported tastes: An approach consistent with the consumer's decision making process. Journal of Economic Psychology 30, 622-633.

FERRAN, J.L. (2007). Gestió d'una empresa audiovisual. Segunda edición. Barcelona: Eureca Media.

GOMERY, D. (1986). Hollywood: El sistema de estudios. Madrid: Verdoux.

GOMERY, D. (1998). Contemporary Hollywood Cinema. (Ed.). Steve Neale \& Murray Smith). London: Routledge.

GUBACK, T. (1980). La industria internacional del cine. Madrid: Fundamentos.

HILL, C. y JONES, G. (2009). Administración estratégica (8. ${ }^{\mathrm{a}}$ ed.). México: McGraw- Hill. 
KOONTZ, H., WEIHRICH, H. y CANNICE, M. (2012). Administración: una perspectiva global y empresarial (14. ${ }^{\mathrm{a}}$ ed.). México: McGraw-Hill.

LINARES PALOMAR, R. (2008). El uso del marketing cinematográfico en la industria del cine español. Álvarez Monzoncillo, J. M. (Dir.) Universidad Rey Juan Carlos.

MATAMOROS, D. (2009). Distribución y marketing cinematográfico. Manual de primeros auxilios. . Barcelona: Publicacions i Edicions de la Universitat de Barcelona.

MONZONCILLO, J. M. (2003). Cine: riesgos y oportunidades se equilibran ante el cambio digital. Hacia un nuevo sistema mundial de comunicación. En Bustamante, E. (Ed.) Las industrias culturales en la era digital, 85-110 .Barcelona: Gedisa

MOUL, C. (2008). Retailer entry conditions and wholesaler conduct: The theatrical distribution of motion pictures. International Journal of Industrial Organization, (26), 966-983.

PORTER, M. (2009). Ser competitivo. Barcelona: Deusto.
ROBINS, J. A. (1993). "Organization as strategy: restructuring production in the film industry". Strategic Management Journal, 14, 103-118.

SHERMAN (1890) Sherman Antitrust Act, first legislation enacted by the U.S. Congress (1890) to curb concentrations of power that interfere with trade and reduce economic competition.

SCOTT, A. J. (2002). A New Map of Hollywood: The Production and Distribution of American Motion Pictures. Regional Studies, 36, (9), 957-975.

SCOTT, A. J. (2004). Hollywood and the world: the geography of motion-picture distribution and marketing. Review of International Political Economy, 11 (1), 33-61.

SEGOVIA, A. I. (2004) "La fábrica de sueños" vista desde la economía política". Redes.com,(1), 87-95.

WASKO, J. (1994). Hollywood in the Information Age: Beyond the Silver Screen. Univestity of Texas Press.

WIESE, M. (1989). Film \& Video Marketing. Stoneham: M. Wiese Productions. 